Research Article

\title{
Response Analysis of Submerged Floating Tunnel Hit by Submarine Based on Smoothed-Particle Hydrodynamics
}

\author{
Gang Luo $\mathbb{D}^{1},{ }^{1}$ Shaokang Pan $\mathbb{D}^{1},{ }^{1}$ Yulong Zhang, ${ }^{1}$ and Liang Chen ${ }^{2}$ \\ ${ }^{1}$ School of Highway, Chang'an University, Xi'an, Shaanxi, 710064, China \\ ${ }^{2}$ Guangxi Communications Investment Group Co., Ltd, Nanning, Guangxi, 530000, China
}

Correspondence should be addressed to Gang Luo; luogang@chd.edu.cn

Received 9 April 2019; Accepted 20 May 2019; Published 9 June 2019

Academic Editor: Luca Landi

Copyright (c) 2019 Gang Luo et al. This is an open access article distributed under the Creative Commons Attribution License, which permits unrestricted use, distribution, and reproduction in any medium, provided the original work is properly cited.

This paper presents the theoretical investigation on the damage of the submerged floating tunnel (SFT) under extreme loads. Water was modeled by smoothed-particle hydrodynamics (SPH). Anchor cables, SFT, and submarine were modeled by the finite element method (FEM). Penetrating phenomenon in the calculation process was achieved by the penalty function, and the fluidsolid coupling effect was also considered in the simulation. The process of a submarine striking on the SFT was studied based on the commercial software. The relationships between the energy of the water, submarine, and SFT were studied. The structural and human damages were evaluated using the kinematics and kinetic parameters of the SFT according to the relevant criterion. The results indicate that the SPH-FEM coupling method is suitable to investigate the impact of the SFT in the water. The initial kinetic energy of the submarine is mainly converted into kinetic energy of the water and internal energy of the tunnel. The kinematic parameters at the impact point reach a peak value. The kinematic parameters at the anchor cables reach the minimum value, so the anchor cables can inhibit the development of disaster significantly. The SPH-FEM coupling method can be helpful for collision and explosion analysis of the SFT.

\section{Introduction}

A submerged floating tunnel (SFT), also known as an Archimedes bridge, is mainly composed of pipe bodies and fixtures (including fixed supports, anchor cables, or buoys) and bulkhead joints suspended at a certain depth below the water surface. As a result of limited influence of weather, small longitudinal slope, and no influence on surface traffic, the SFT has become a preferred traffic structure across long and deep water [1-3].

SFTs may be subjected to extreme loads such as earthquakes and explosions inside and outside the pipeline, wrecks, or collisions with underwater submersibles during operation, which should be involved as a necessary process for the structural safety. Morita et al. [4], Carpaneto [5], Fogazzi and Perotti [6], Chen and Huang [7], Martinelli et al. [8], Dong et al. [9], and Lee et al. [10] analyzed the response of a submerged floating tunnel and an anchor system under the action of an earthquake using the Green function, large mass method, response spectrum method, pseudoexcitation method, and finite element method (FEM). Seo et al. [11, 12] and Luo et al. [13] used ANSYS/LS-DYNA software to analyze the dynamic response of an SFT under the underwater explosion condition. Hong and Lee [14], Zhang et al. [15], and Xiang and Yang [16, 17] studied the response analysis of an SFT under impact and collision loads based on a simplified elastic support beam model of FEM. Wu and Mei [18] discussed the effects of hydrodynamics, earthquakes, and structural parameters on the dynamic response of tunnel anchors under seismic conditions. Because a few studies have been conducted on SFTs under submarine collision conditions and a numerical analysis based on the arbitrary Lagrange-Eulerian is inefficient due to the model size and calculation cost, smoothed-particle hydrodynamics (SPH) and FEM coupling methods were proposed to analyze the collision response of an SFT.

The SPH program was applied to simulate the impact issue [19]. Two impact models, which included a frontal 
impact and an oblique impact, were simulated. The results showed that the SPH method was suitable for dealing with large deformation problems. It was demonstrated that the SPH method could be applied to solving impact mechanics problems. Xu et al. [20] used the SPH method to simulate the collision process of projectiles on thin target plates. The shape and characteristics of the debris cloud coincide with the experiment results, indicating the effectiveness of the SPH method on the simulation of this mechanics problem. Based on $\mathrm{SPH}$ theory, Yang et al. [21] studied the influence of water surface explosion. The results verified that the SPH method is suitable for the evaluation of the compressible multimedia flow.

In summary, some conditions of the SFT under extreme environments have been focused all over the world, including the overall response of the tunnel and the influence of different anchor cable forms. However, research on human safety in tunnels after collision is still limited. Therefore, it will be very interesting to conduct further study on the impact of SFT according to the SPH.

\section{Basic Principle of the SPH Method}

2.1. SPH Method. The SPH method differs from traditional numerical methods based on a discrete grid (such as the finite difference and FEM). The SPH method was first proposed in 1977 [22] and is a pure Lagrangian form of a meshless particle method. The method discretizes a continuum into a group of particles with a certain mass and speed. The field function value of all particles was assessed by an interpolation function, and the spatial derivative was deduced without relying on the grid. The phenomenon of grid entanglement and distortion was avoided, and a computational overflow was from a large interface deformation. Therefore, the SPH method has significant advantages in evaluation of the large deformations.

\subsection{Calculation Principle of SPH Method. The SPH method} is mainly based on interpolation theory. Each particle represents an interpolation point of an available physical property. Using a specific interpolation function, $W(x, h)$, macro $f(x)$ (such as the speed and displacement) is obtained from the form of integral estimation. In solving domain $D$, the values of the relative variables at space $x$ are calculated by field function:

$$
f(x)=\int_{D} f\left(x^{\prime}\right) W\left(x-x^{\prime}, h\right) d x^{\prime},
$$

where $W$ is a smoothing function and $h$ is the smoothing length, which stipulates the influence domain of $W$. The weight functions include Gaussian and cubic spline functions, which meet the conditions of regularization and a compact support. Formula (1) is an approximate expression of the continuous form of particles, which can be rewritten as the discrete form [23] of particle $j$ in the influence domain of particle $i$ at $x$ :

$$
f(x)=\sum_{j=1}^{N} \frac{m_{j}}{\rho_{j}} f\left(x_{j}\right) W\left(x-x_{j}, h\right),
$$

where $N$ is the amount of particles within the influence domain of particle $i$ and $m$ and $\rho$ correspond to the mass and density of the particle, respectively.

\section{Calculation Model and Parameters}

3.1. Calculation Model. The parameters of an SFT in the Sonnen Strait, Norway, are presented in this paper. The relevant indicators of the pipe body, anchor cables, and submarine are shown in Table 1 . The geometry diagram of the analytical model is shown in Figure 1, which included 606,139 elements, 696,443 nodes, and 331,719 SPH particles. The SFT, submarine, and anchor cables were modeled by the FEM. Figure 2 is the image of the finite element model, in which a large number of particles are removed so as to improve the quality. Figure 3 is the model's cutaway view. The water was modeled by SPH, where the diameter of the $\mathrm{SPH}$ particles was set to $1 \mathrm{~m}$. The boundary of the water model and the entire model were considered as the radiation boundary, which came from the SFT suspended in the sea and usually corresponded to the sea surface [24]. The whole model was built using HyperMesh. The dimension of the mesh was smaller than 30 meters of the impact of the tunnel, and the mesh size of this part was $0.2 \mathrm{~m}$. The rest of the tunnel was made by graded meshing. Farther away from the impact area, the size of the mesh was larger. The reason for this meshing method was that if the deformation of the impact zone is large, refining the mesh can improve the accuracy of the solution, and if the deformation of the rest is relatively small, the solution efficiency could be improved by increasing the mesh size appropriately. The bow and stern of the submarine are both hemispherical with a radius of $8 \mathrm{~m}$ and $4 \mathrm{~m}$, respectively. The tunnel, submarine, and anchor cables were made of Q345 based on the solid elements. The two ends of the tunnel were fixed, and the anchor cables were 25 meters from the ends. As Figure 2 shows, the direction longitudinally along the tunnel was the $Z$-direction, the vertical direction was the $Y$-direction, and the direction of the submarine movement (impact direction) was the $X$ direction. The impact point was located in the middle of the tunnel.

3.2. Calculation Method. In the calculation process, the force between the particles and the meshes was transmitted by using the penalty function constraint; therefore, the fluidstructure interaction was realized. Figure 4 shows the interface diagram of meshes and particles.

The contact coupling algorithm allows the mesh and particles to interact without penetrating. The particles should be checked for whether the penetration behavior happened to the master surface before each step. If there was no penetration, no treatment was required. Otherwise, the penetration distance $l$ was calculated using the particle radius and the distance from the center of the particle to the interface. In order to eliminate the penetration, the contact force $f$ was calculated according to the size of $l$ to act on the particles [25]. The direction of $f$ was opposite to the direction of penetration. The $f$ was named the penalty function value, 
TABLE 1: Parameters of the models.

\begin{tabular}{|c|c|c|}
\hline Parts & Parameters & Values \\
\hline \multirow{5}{*}{ Pipe body } & Length (m) & 100.00 \\
\hline & Outer diameter $(\mathrm{m})$ & 12.04 \\
\hline & Wall thickness (m) & 0.26 \\
\hline & Depth $(\mathrm{m})$ & 30.00 \\
\hline & Quality $(t / \mathrm{m})$ & 76.00 \\
\hline \multirow{5}{*}{ Anchor cable } & Length (m) & 70.00 \\
\hline & Diameter $(\mathrm{m})$ & 0.40 \\
\hline & Poisson's ratio & 0.30 \\
\hline & Elastic modulus $(\mathrm{Pa})$ & $2.07 E 11$ \\
\hline & Density $\left(\mathrm{kg} / \mathrm{m}^{3}\right)$ & 7900.00 \\
\hline \multirow{5}{*}{ Submarine } & Quality $(t)$ & 860.00 \\
\hline & Length (m) & 15.00 \\
\hline & Distance from the tunnel $(\mathrm{m})$ & 2.50 \\
\hline & Wall thickness $(\mathrm{m})$ & 0.40 \\
\hline & Initial speed $(\mathrm{m} / \mathrm{s})$ & 5.00 \\
\hline
\end{tabular}

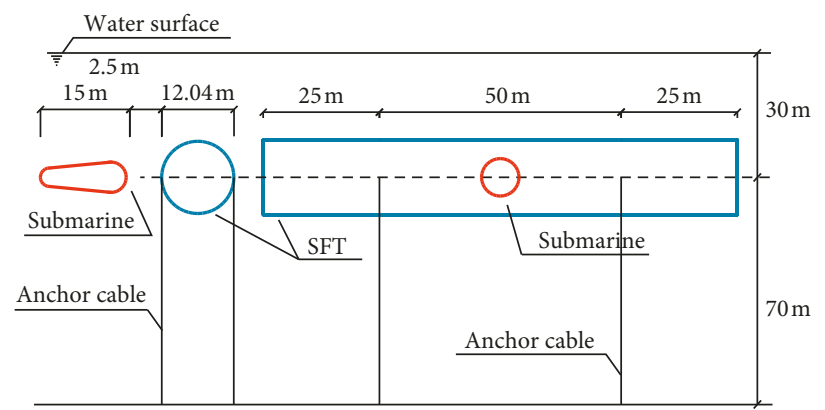

Figure 1: Geometric model.

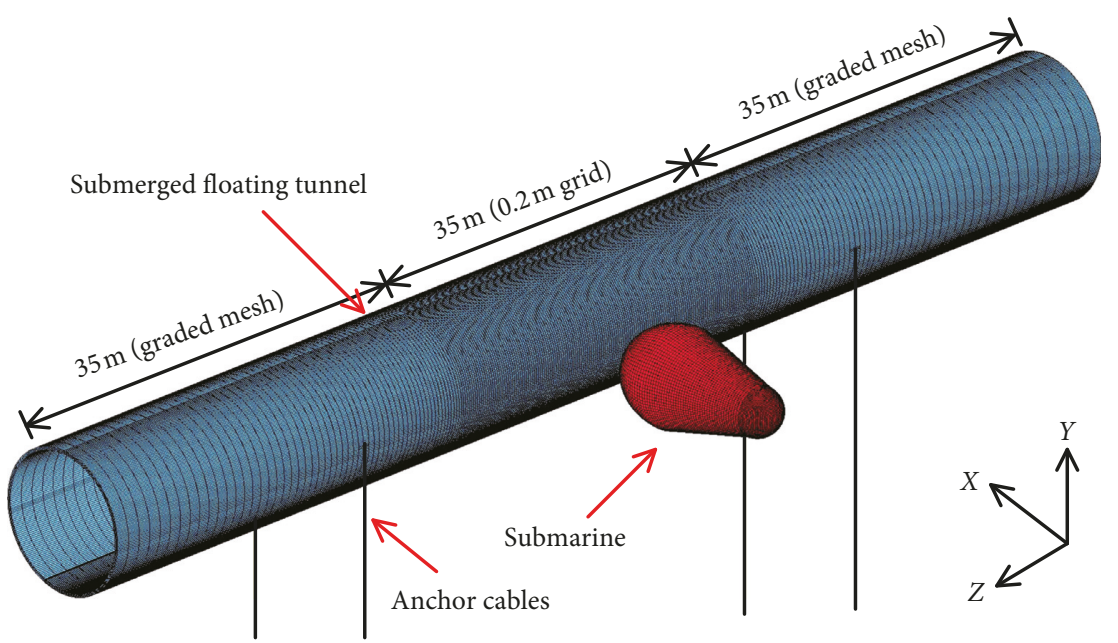

FIGURE 2: Finite element method model.

which could limit the penetration of particles and achieve the fluid-structure interaction.

$$
\begin{aligned}
d & =\sqrt{\frac{m}{2 \pi^{2} \rho r}}, \\
f_{\mathrm{n}} & =f_{\mathrm{s}} k l \overrightarrow{\mathbf{n}}, \\
f_{\mathrm{t}} & =\left|f_{\mathrm{s}}\right| \mu,
\end{aligned}
$$

where $d$ is the particle radius, $r$ is the radial coordinate, $f_{\mathrm{n}}$ is the normal contact force of the interface, $k$ is the master surface stiffness, $f_{\mathrm{s}}$ is the scale factor of $k, \mathbf{n}$ is the normal unit vector of the grid unit, $f_{\mathrm{t}}$ is the tangential contact force of the interface, and $\mu$ is the coefficient of friction of the particles at the contact surface.

3.3. Constitutive Parameters. The submarine and anchor cables were made of an elastic material, the tunnel was made 


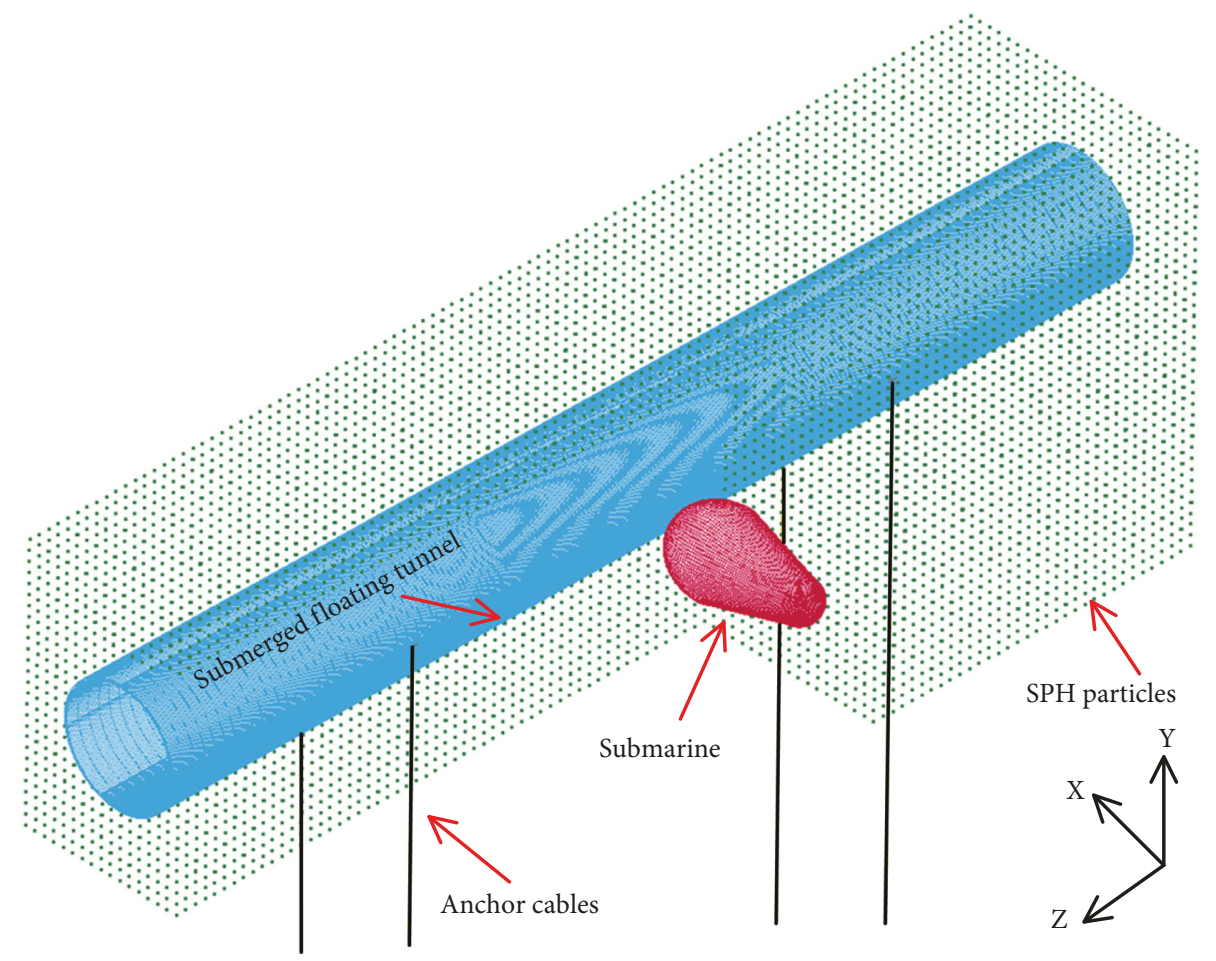

Figure 3: Cutaway view of the model.

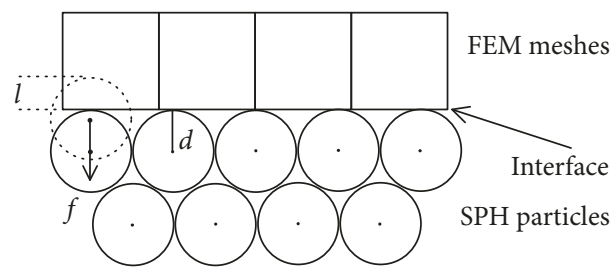

FIGURE 4: Interface diagram of mesh and particle.

of an elastoplastic material, and the Cowper-Symonds model was used to illustrate the influence of the strain rate on the yield stress. The model equation is as follows:

$$
\sigma_{y}=\left[1+\left(\frac{\varepsilon}{C}\right)^{1 / p}\right]\left(\sigma_{0}+\beta E_{p} \varepsilon_{p}^{\text {eff }}\right),
$$

where $\sigma_{y}$ is the yield stress, $\sigma_{0}$ is the initial yield stress, $\varepsilon$ is the strain rate, $\beta$ is the hardening parameter, $C$ and $P$ are the strain rate parameters $\left(C=40, P=5\right.$ for steel), $\varepsilon_{p}^{\text {eff }}$ is the effective plastic strain, and $E_{p}$ is the plastic hardening modulus [26].

The water is defined using the empty material model and the equation of state is as follows:

$$
\begin{aligned}
P= & \frac{\rho_{0} c^{2} \mu\left[1+\left(1-\left(\gamma_{0} / 2\right)\right) \mu-(a / 2) \mu^{2}\right]}{\left[1-\left(S_{1}-1\right) \mu-S_{2}\left(\mu^{2} /(\mu+1)\right)-S_{3}\left(\mu^{3} /(\mu+1)^{2}\right)\right]^{2}} \\
& +\left(\gamma_{0}+a \mu\right) E,
\end{aligned}
$$

where $P$ is the pressure, $\rho_{0}$ is the density of water at normal temperature, $c$ is the intercept of $\mu_{\mathrm{s}}-\mu_{\mathrm{p}}$ (shock wave speed-particle speed) curve, $S_{1}, S_{2}$, and $S_{3}$ are the slope coefficients of the $\mu_{\mathrm{s}}-\mu_{\mathrm{p}}$ curve, $\mu$ is the initial relative specific volume, $\rho$ is the density of water after an explosion, $\gamma_{0}$ is the Gruneisen coefficient, $a$ is the first-order volume correction coefficient of $\gamma_{0}$, and $E$ is the material internal energy. Some parameters of which are shown in Table 2 [27].

\section{Response Analysis of SFT}

4.1. Analysis of Energy. Figure 5 shows the time history of the kinetic energy, internal energy, total energy, and hourglass energy of the system. It was generally considered that when the hourglass energy was less than $5 \%$ of the peak internal energy, the calculation result was stable [28]. In the figure, the peak internal energy was $7.53 \times 10^{6} \mathrm{~J}$ and the maximum hourglass energy was $0.31 \times 10^{6} \mathrm{~J}$, which accounted for $4 \%$ of the peak internal energy. Therefore, from the perspective of energy conservation and hourglass energy control, the simulation results were considered reasonable.

Figure 6 shows the energy relation among the water, submarine, and tunnel. The energy of the anchor cable is too small to be analyzed in the figure. It was found that the front part of the submarine was $2.5 \mathrm{~m}$ away from the tunnel at the beginning of the calculation. The total energy of the system was the initial kinetic energy of the submarine, the value of which was $10.8 \times 10^{6} \mathrm{~J}$. Prior to collision ( $\left.0.55 \mathrm{~s}\right)$, owing to the resistance of water, the kinetic energy of the submarine was attenuated at $7.5 \times 10^{6} \mathrm{~J}$ and the total energy was reduced by $31 \%$. At this time, the kinetic energy and internal energy of the water are $2.6 \times 10^{6} \mathrm{~J}$ and $0.6 \times 10^{6} \mathrm{~J}$, respectively. The total energy of the water was almost the same as the decrease of the kinetic energy of the submarine. After the collision system was stabilized, the total energy of the water was 
TABLe 2: Material parameters and coefficients in Gruneisen equation of state of water.

\begin{tabular}{lcccccc}
\hline$\rho_{0}\left(\mathrm{~kg} / \mathrm{m}^{3}\right)$ & $c(\mathrm{~m} / \mathrm{s})$ & $\gamma_{0}$ & $a$ & $S_{1}$ & $S_{2}$ & $S_{3}$ \\
\hline 1000 & 1480 & 0.4934 & 1.3937 & 2.56 & -1.986 & 0.2268 \\
\hline
\end{tabular}

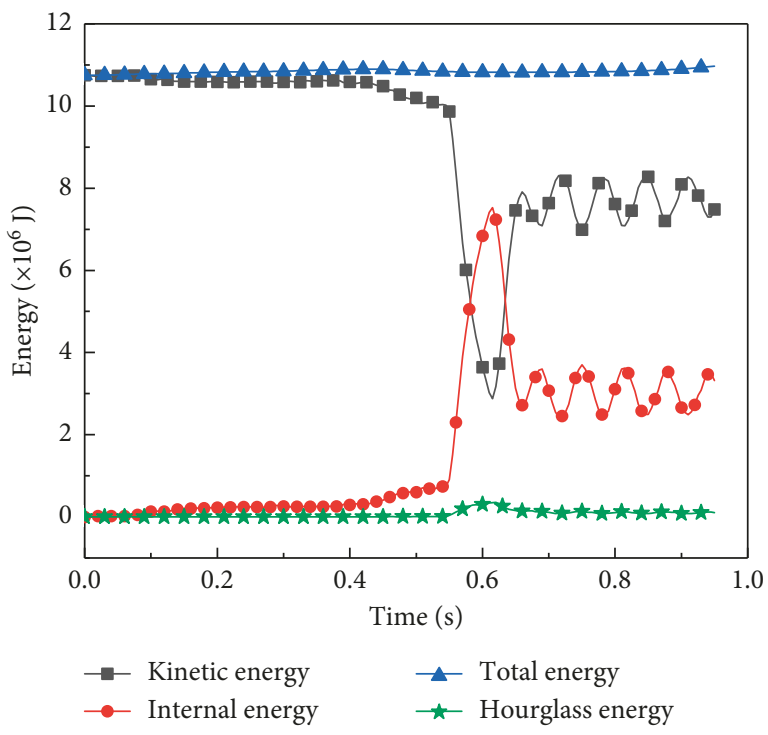

FIgURe 5: Global energy.

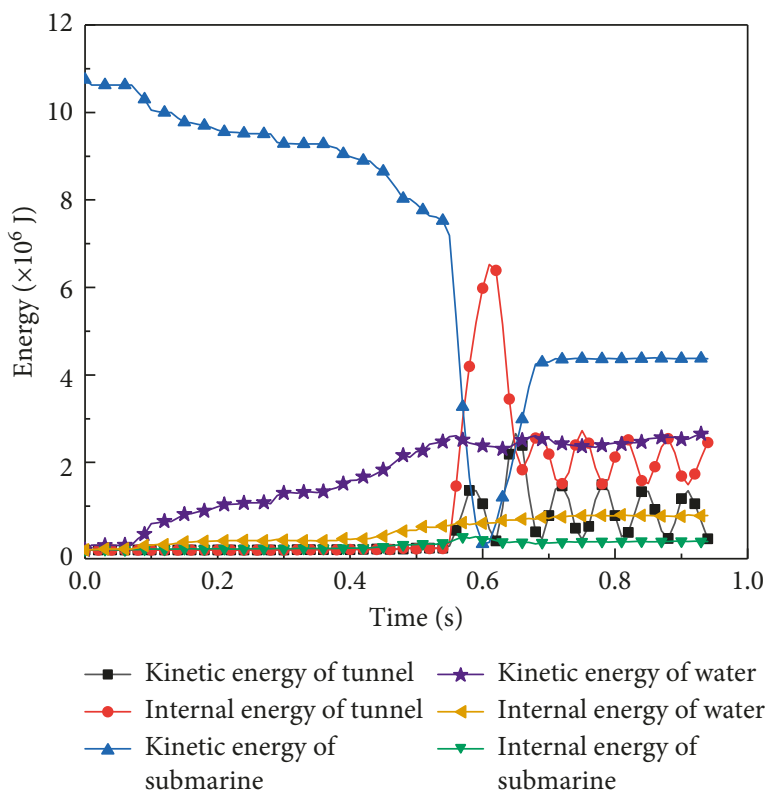

FIGURE 6: Energy relationship between the tunnel and submarine.

$3.2 \times 10^{6} \mathrm{~J}$, accounting for $30 \%$ of the initial kinetic energy of the submarine, which showed that the resistance of the water in the impact process cannot be ignored. In same time, the kinetic energy of the submarine was $4.4 \times 10^{6} \mathrm{~J}$. Most of this kinetic energy was converted into internal energy $\left(2.2 \times 10^{6} \mathrm{~J}\right)$ and kinetic energy $\left(0.8 \times 10^{6} \mathrm{~J}\right)$ of the tunnel. In the collision process, the tunnel absorbed $40 \%$ of the total
TABLE 3: Division of physical injury areas.

\begin{tabular}{lcc}
\hline Area determinants & $\begin{array}{c}\text { Impact max } \\
\text { speed }(\mathrm{m} / \mathrm{s}) \\
(T<15 \mathrm{~ms})\end{array}$ & $\begin{array}{c}\text { Impact average } \\
\text { acceleration }\left(\mathrm{m} / \mathrm{s}^{2}\right) \\
(T>15 \mathrm{~ms})\end{array}$ \\
\hline Safety area & $<2.2$ & $<140$ \\
Light injury area & $2.2 \sim 3.0$ & $140 \sim 200$ \\
Moderate injury area & $3.0 \sim 4.0$ & $200 \sim 250$ \\
Severe injury area & $>4.0$ & $>250$ \\
\hline
\end{tabular}

energy, as the main form of absorption, which was the internal energy generated by the deformation of the tunnel wall.

4.2. Analysis of Kinematic Results. Safety Limits for the Effects of Surface Ship Shock on Man [29] (GJB 2689-96) proposed some regulations about safety. In this standard, the human body is in a standing posture.

The time when the ship's specific part got the maximum speed was set to $T$ after the ship was hit. If $T$ was less than $15 \mathrm{~ms}$, the injury of the passengers would be induced by the impact speed and the degree about passengers' injury would be determined by the average impact acceleration. According to the speed and acceleration, the areas can be divided into a safety zone, light injury zone, moderate injury zone, and severe injury zone, the specific standards of which are listed in Table 3.

Figure 7 shows the maximum displacement of the impact direction (which in the following is simply referred as the $X$-direction) at different positions along the longitudinal direction of the tunnel, and Figure 8 shows a time-history curve for the displacement of the tunnel impact point in the $X$-direction.

In Figure 7, the maximum displacement at impact point A (longitudinal position of $0 \mathrm{~m}$ ) was $118.8 \mathrm{~mm}$, and the maximum displacement from the impact point along the longitudinal direction of the tunnel to both ends of the tunnel $(50 \mathrm{~m})$ generally attenuated in an inverted "V"shaped trend, with the two sides being symmetric. The anchor cable was connected to the tunnel at point $\mathrm{B}(\mathrm{C})$, and the displacement of the two points was $11.4 \mathrm{~mm}$ in the $X$ direction. Since the tunnel was pulled by the anchor cable, further deformation of the tunnel was restrained and minimum value occurred at point $B(C)$. Both ends of the tunnel were fixed, causing the displacement to be zero.

In Figure 8, after a collision at $0.55 \mathrm{~s}$, the displacement of point $\mathrm{A}$ increases obviously. At $0.60 \mathrm{~s}$, the displacement in the $X$-direction reached the maximum value. The displacement then decreased significantly. After the submarine separated from the tunnel at $0.68 \mathrm{~s}$, the displacement of the point A reciprocated with time and the amplitude gradually decreased. Figure 9 shows the displacement nephograms of the tunnel at 0.55 and $0.60 \mathrm{~s}$.

In Figure 10, the speed of point A was the largest, with a value of $3.18 \mathrm{~m} / \mathrm{s}$. The maximum speed in the $X$-direction from point $\mathrm{A}$ to the tunnel ends gradually decreased symmetrically. Point B (C) got the local minimum of $0.45 \mathrm{~m} / \mathrm{s}$. 


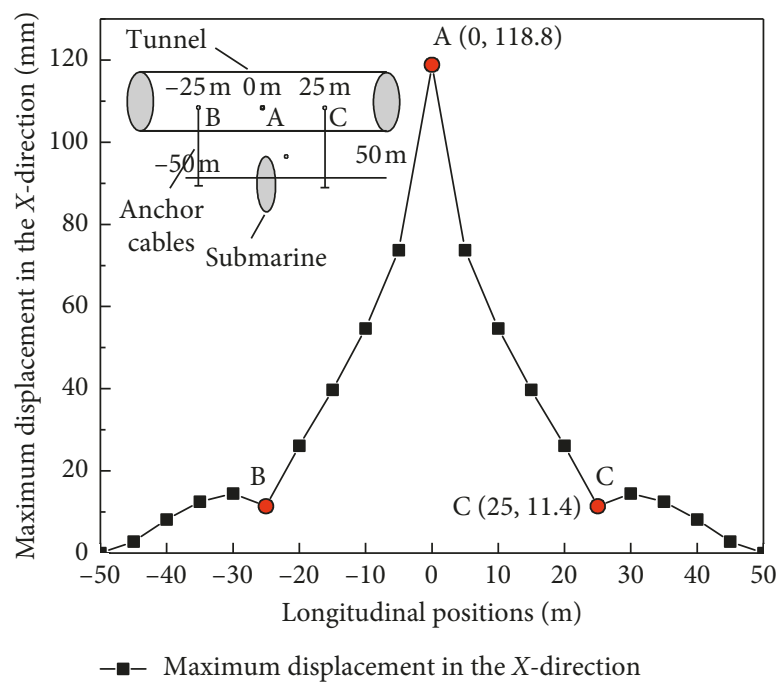

Figure 7: Maximum $X$-direction displacement at different longitudinal positions.

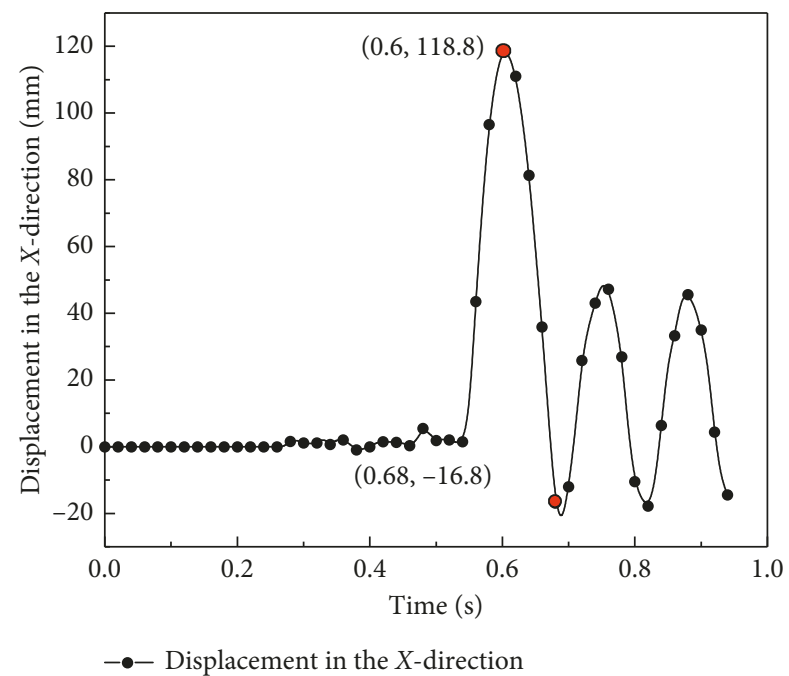

Figure 8: Time-history curve of $X$-direction displacement at point A.

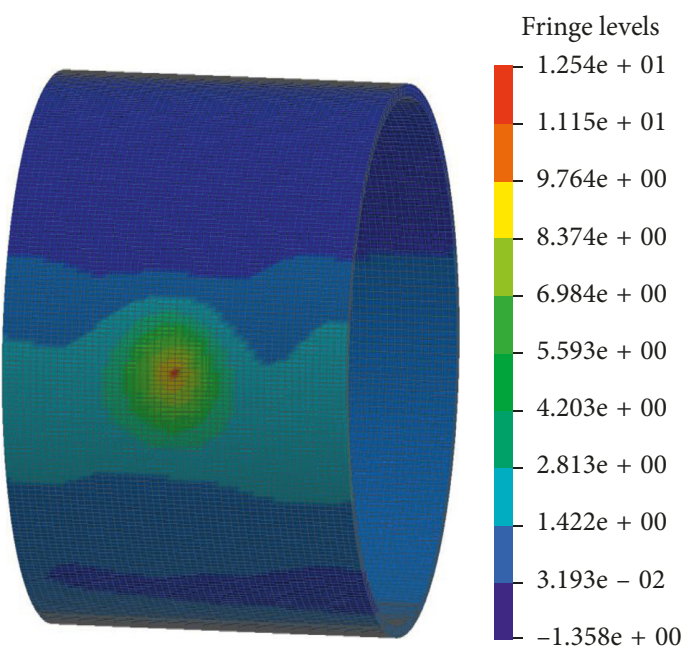

(a)

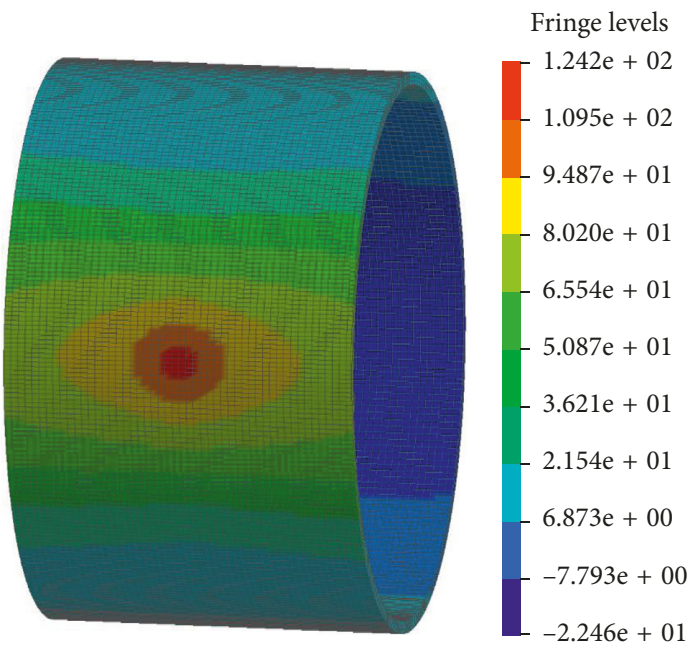

(b)

FIGURE 9: Displacement nephograms of point A within $10 \mathrm{~m}$. (a) $0.55 \mathrm{~s}$ nephogram. (b) $0.60 \mathrm{~s}$ nephogram. 


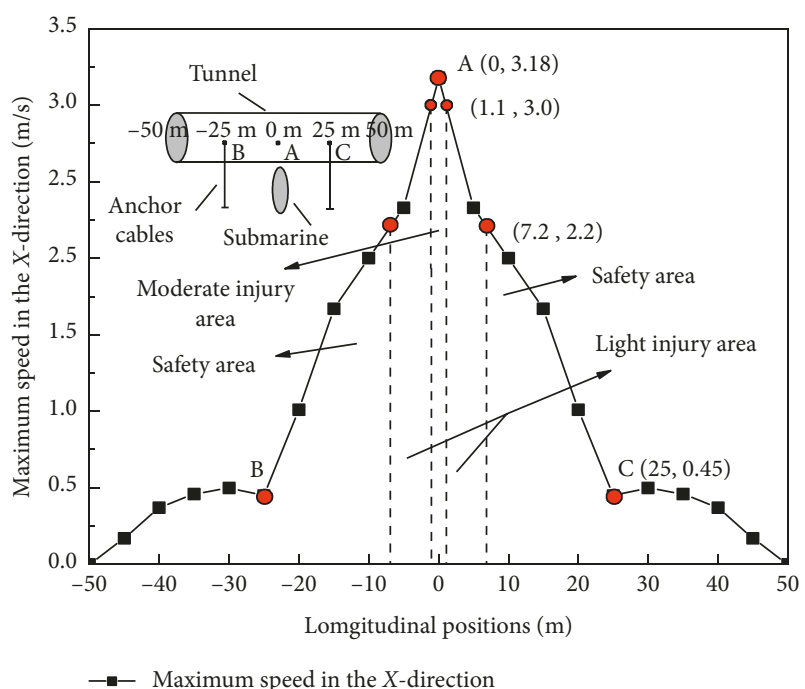

Figure 10: Maximum $X$-direction speed at different longitudinal positions.

As shown in Figure 11, after collision, the speed of point A increased significantly. At $0.56 \mathrm{~s}$, the $X$-direction speed reached a maximum value of $3.18 \mathrm{~m} / \mathrm{s}$ (which was earlier than the time that maximum displacement occurred). Then, the speed of point A reciprocated with time and the amplitude decreased gradually. Figure 12 shows the speed nephograms at 0.56 and $0.62 \mathrm{~s}$.

Referring to the evaluation criteria of the effects of impact on the human body in Table 3, the safety of the human body when the submarine impacted the tunnel was analyzed. There was $T=10 \mathrm{~ms}$ between the start of the impact process $(0.55 \mathrm{~s})$ and the time when speed reaching the maximum $(0.56 \mathrm{~s})$, less than $15 \mathrm{~ms}$. Accordingly, the impact speed played a decisive role in estimating the human's injury. The maximum speed of point $\mathrm{A}$ at this moment $(0.56 \mathrm{~s})$ was $3.18 \mathrm{~m} / \mathrm{s}$. A human body of $2.2 \mathrm{~m}$ near the point acquired moderate injury. According to the maximum speed at different areas along the longitudinal direction of the tunnel, the different degrees of the human's injury were classified into three categories (Figure 13).

Please note that the displacement and velocity of the collision point cannot represent the motion state of the pipe of the SFT. Pedestrian walkways and maintenance passages on both sides may be reserved during the design of the SFT. Pedestrians and maintenance workers will appear on both sides of the side walls of the tunnel. Based on the most dangerous and worst conditions, the parameters of the collision point are applied to evaluate the injury of the human body.

In Figure 14, the acceleration at point $A$ reached $148.3 \mathrm{~m} / \mathrm{s}^{2}$. Meanwhile, the acceleration gradually decreased at positions farther from the impact point, where the local minimum acceleration at $\mathrm{B}(\mathrm{C})$ was $26 \mathrm{~m} / \mathrm{s}^{2}$. The acceleration of segments $\mathrm{A}$ to $\mathrm{B}$ and $\mathrm{A}$ to $\mathrm{C}$ gradually decreased and then increased slightly before decreasing to zero. The maximum acceleration occurred at $0.68 \mathrm{~s}$ (Figure 15).

4.3. Analysis of Kinetic Results. The impulse could be responded by impact and time. The impact force and

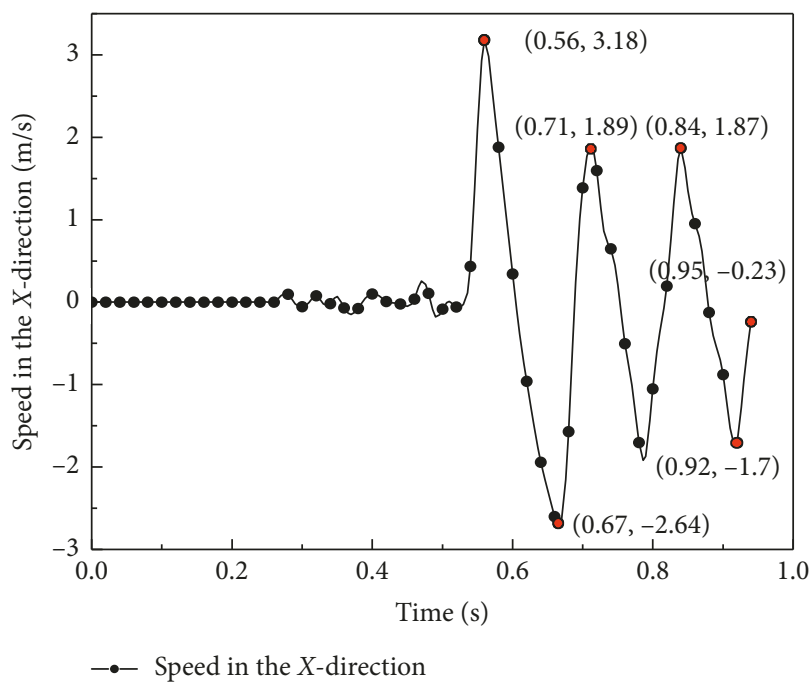

Figure 11: Time-history curve of $X$-direction speed at point A.

impulse are important parameters for evaluating an impact injury. The time-history curve of the impact force is shown in Figure 16. The curve of impact force against penetration depth is shown in Figure 17.

As shown in Figure 16, the impact force rapidly reached the peak value of $72.3 \times 10^{6} \mathrm{~N}$ at the moment of collision and then decreased sharply. The collision process from the start $(0.55 \mathrm{~s})$ to separation $(0.68 \mathrm{~s})$ lasted for $0.13 \mathrm{~s}$. According to the time history of the impact force, the impulse was $6.18 \times 10^{6} \mathrm{~N} \cdot \mathrm{s}$. As shown by the arrow in Figure 17 , the impact force in the early stage (section (1) (2) was proportional to the penetration depth. The impact force and penetration depth of the impact at point (2) were $55.1 \times 10^{6} \mathrm{~N}$ and $43.5 \mathrm{~mm}$, respectively. When the impact force reached the maximum value at point (3) of $72.3 \times 10^{6} \mathrm{~N}$, it decreased gradually. As the tunnel recovered its shape gradually, the submarine moved in the opposite direction and the penetration depth fell back.

Figure 18 shows a longitudinal stress nephogram of the tunnel at $0.59 \mathrm{~s}$. Figure 19 shows a distribution diagram of the stress peak at different longitudinal positions. Figures 20 and 21 indicate the stress and strain time-history curves of point A.

As shown in Figure 19, the stress at point A was the largest, and the stress at joint B (C) between the anchor cable and the tunnel was the second largest. The maximum stress at point $\mathrm{A}$ was $0.541 \mathrm{GPa}$, and the value exceeded the yield stress (345 MPa) of the Q345 steel, and the area (red area of Figure 17) of point A within $5.4 \mathrm{~m}$ had already yielded. The joints and the ends of point $\mathrm{B}(\mathrm{C})(0.284 \mathrm{GPa})$ and $\mathrm{D}(\mathrm{E})$ suffered a maximum stress value due to the stress concentration. The results from Figure 19 indicate that for the large stress, the key parts (such as the joints between anchor cables and tunnels, the connections between two tunnel pipe sections and the connection between tunnel and coastal) should be taken special care, except the impact point. Structural damage might happen when the tunnel encounters an extreme load, which endangers the safety of the tunnel. 


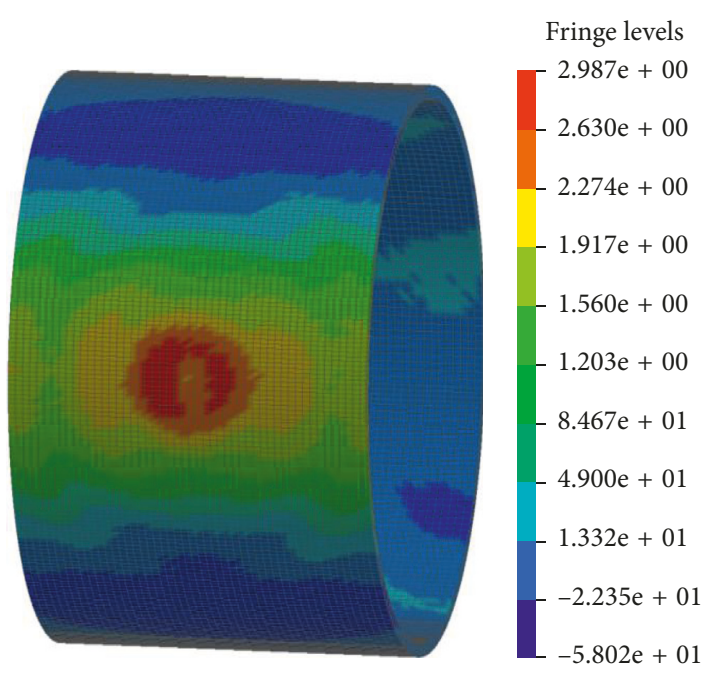

(a)

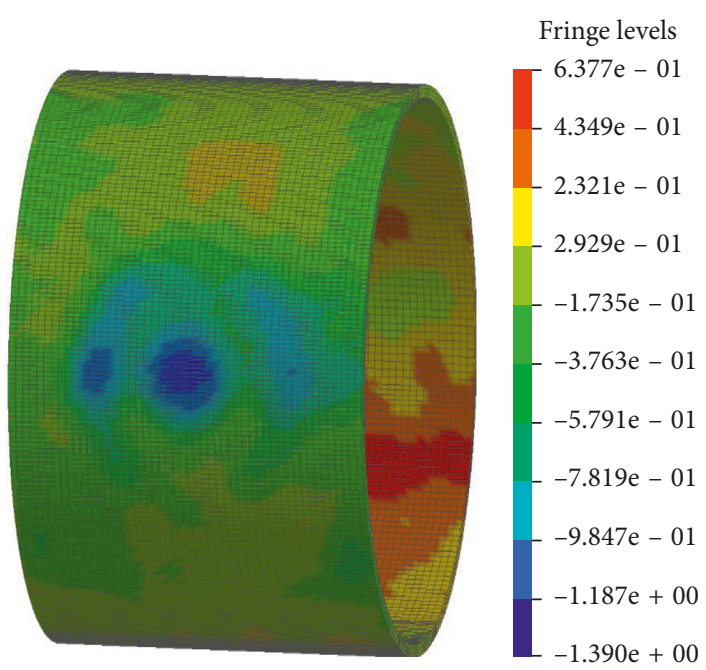

(b)

FIGURE 12: Speed nephograms of point A within $10 \mathrm{~m}$. (a) $0.56 \mathrm{~s}$ nephogram; (b) $0.62 \mathrm{~s}$ nephogram.

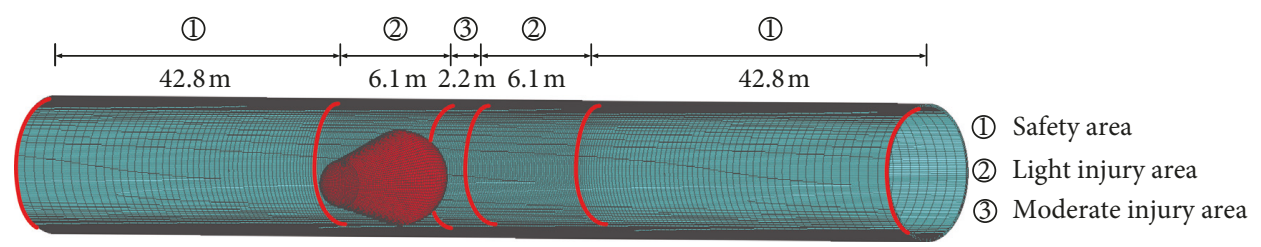

FIgURE 13: Division of physical injury along the tunnel.

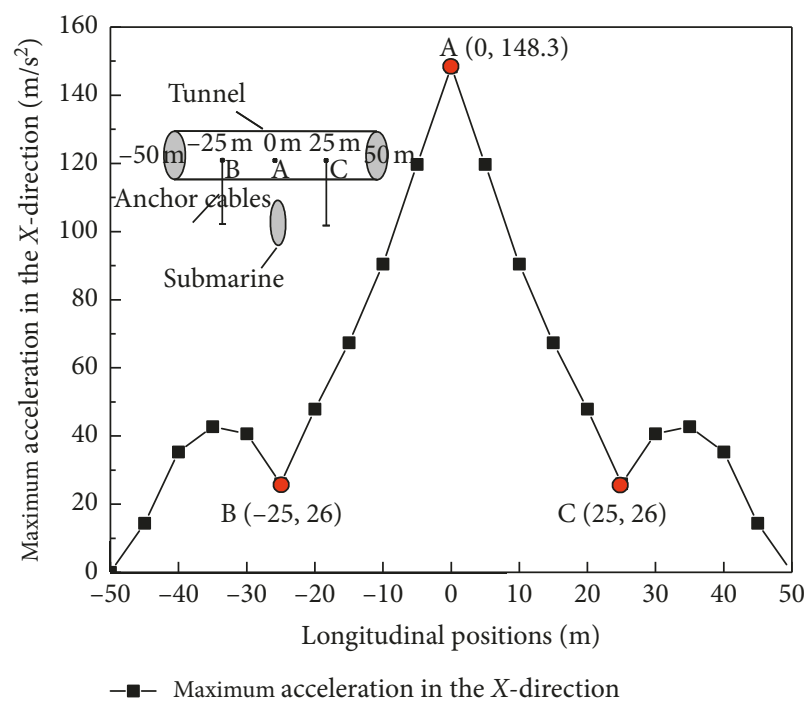

FIGURE 14: Maximum $X$-direction acceleration at different longitudinal positions.

In Figure 20, the stress of point A reached the maximum stress of $0.541 \mathrm{GPa}$ at $0.55 \mathrm{~s}$. With the development of the impact process, the stress decreased sharply. The moment at which the tunnel and submarine were separated $(0.66 \mathrm{~s})$, the minimum stress value of point A was $0.143 \mathrm{GPa}$. After the separation, the stress value was restored approximately to $0.427 \mathrm{GPa}$ and fluctuated in the trend of declination. In

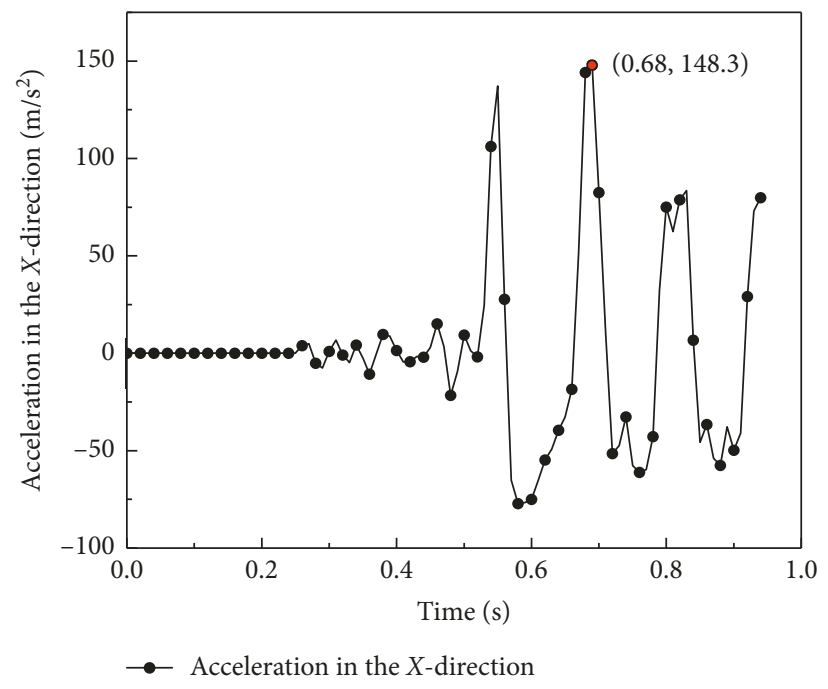

FIgURE 15: Time-history curve of $X$-direction acceleration at point A.

Fig. 21, $0.55 \mathrm{~s}$ was the moment of impact, and the initial strain was 0.00326 . As the submarine moved continually, the strain increased rapidly and maintained a large value of 0.0218 during the impact process $(0.55 \sim 0.68 \mathrm{~s})$. After separation $(0.68 \mathrm{~s})$, the strain was increased slightly to 0.0231 . Figure 22 shows stress nephograms at 0.55 and $0.58 \mathrm{~s}$. Figure 23 shows strain nephograms at 0.55 and $0.66 \mathrm{~s}$. 


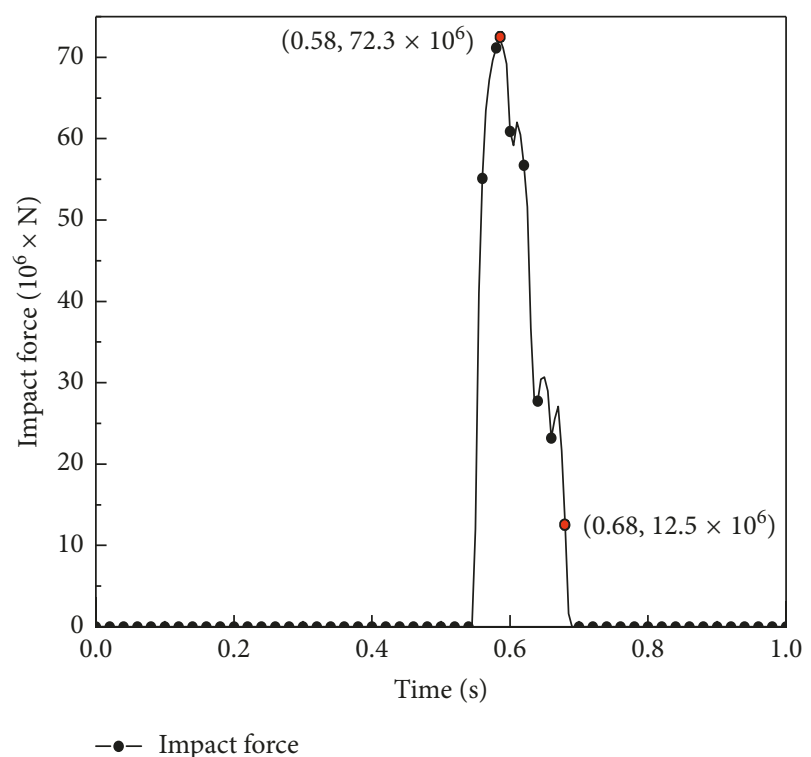

FIgURE 16: Time-history curve of the impact force.

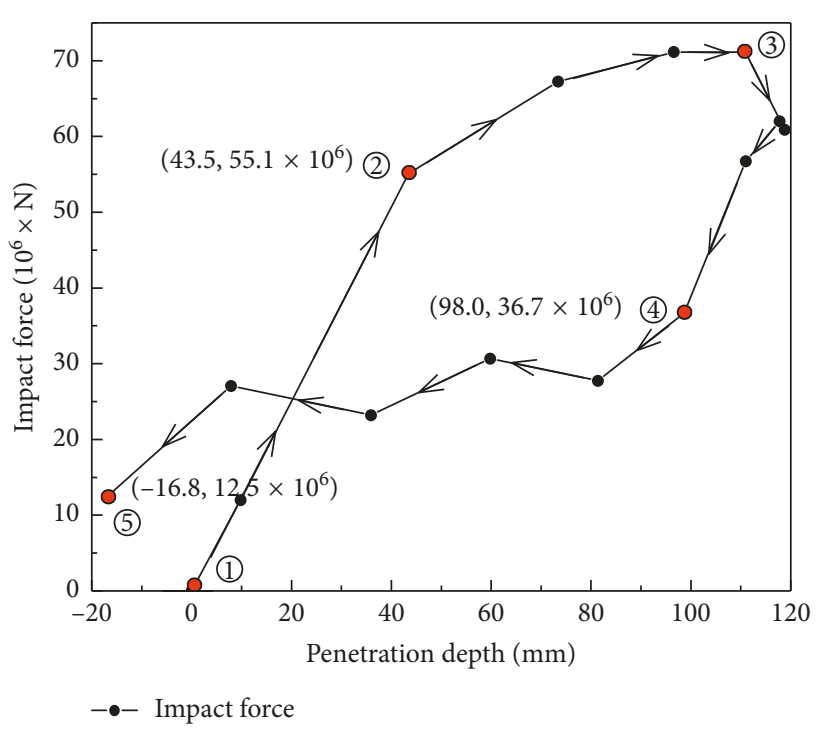

FIgURE 17: Relationship between impact force and penetration depth.

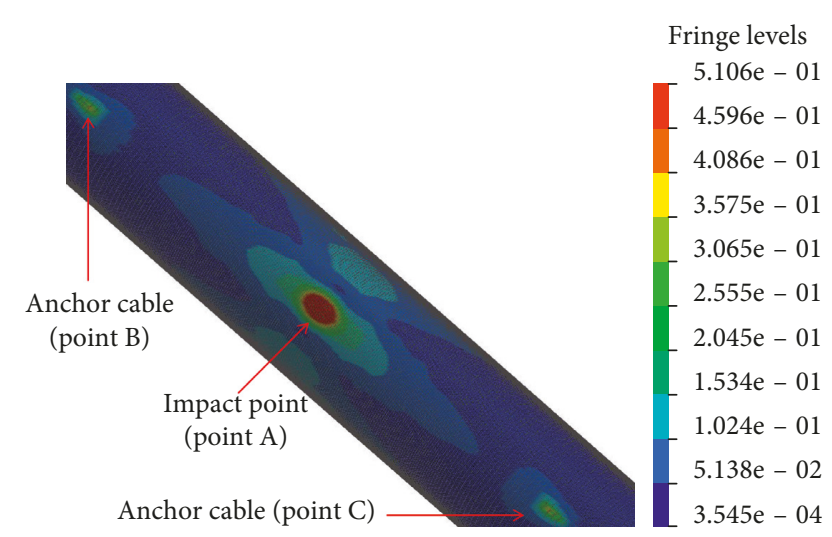

Figure 18: Nephogram of stress along the tunnel at $0.59 \mathrm{~s}$.

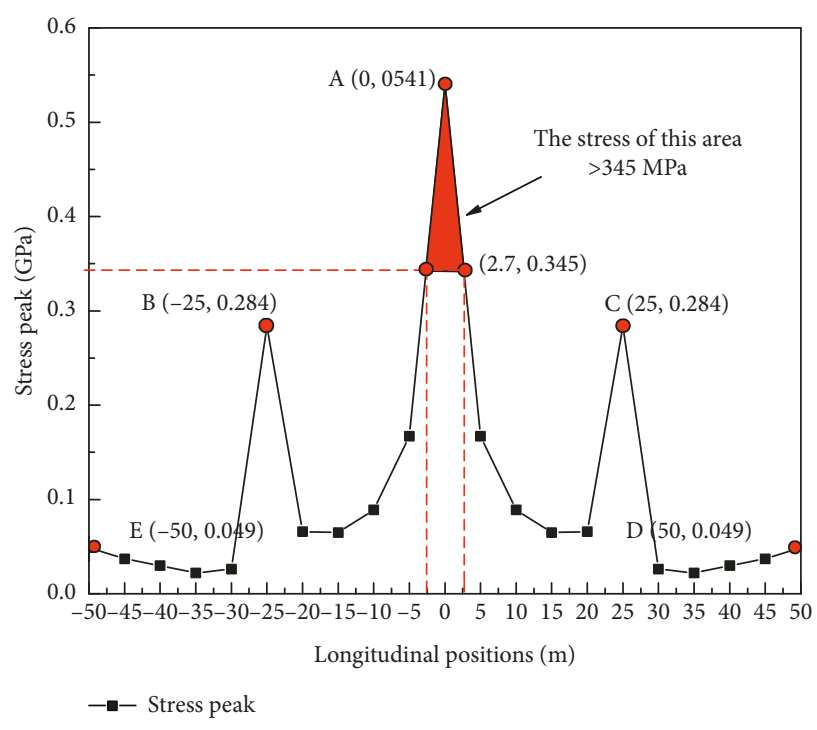

Figure 19: Peak of stress at different longitudinal positions.

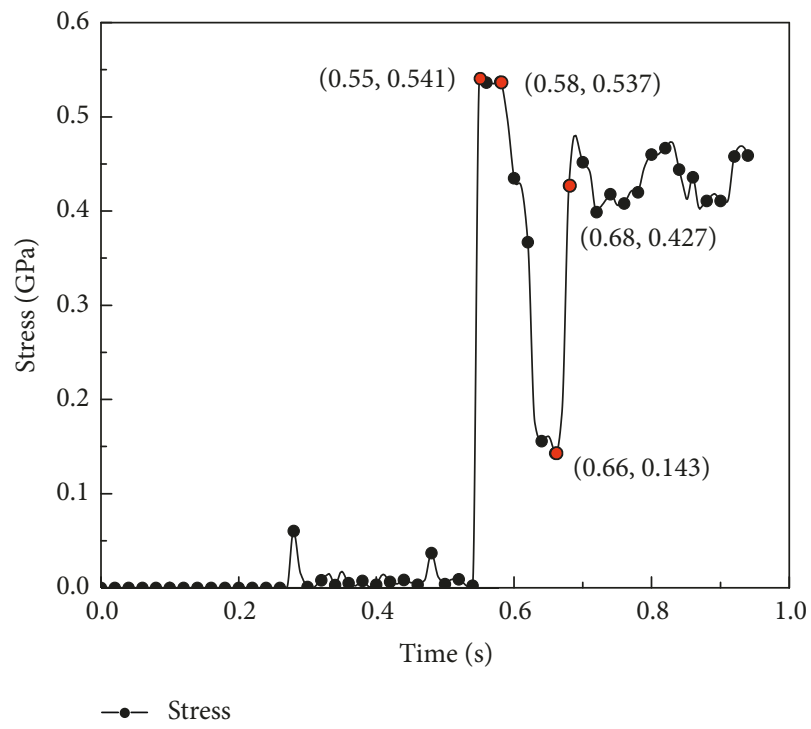

FIgURE 20: Time-history curve of the stress at impact A.

\section{Conclusions}

Based on the principles of the SPH and FEM methods, a model of the SFT impacted by the submarine was established. The variation relationship of related physical quantities of the submarine and tunnel was analyzed based on the ANSYS/LS-DYNA software. The conclusions could be drawn as follows.

The tunnel absorbed $40 \%$ of the total energy and mainly in the form of internal energy generated by the tunnel wall deformation.

The kinematic parameters such as the displacement, speed, and acceleration of the impact point reached the peak value during the impact process. The impacted parameters generally show an inverted "V"-shaped attenuation trend. Moreover, the anchor cables could inhibit the movement of the tunnel to prevent the expansion of a collision disaster. 


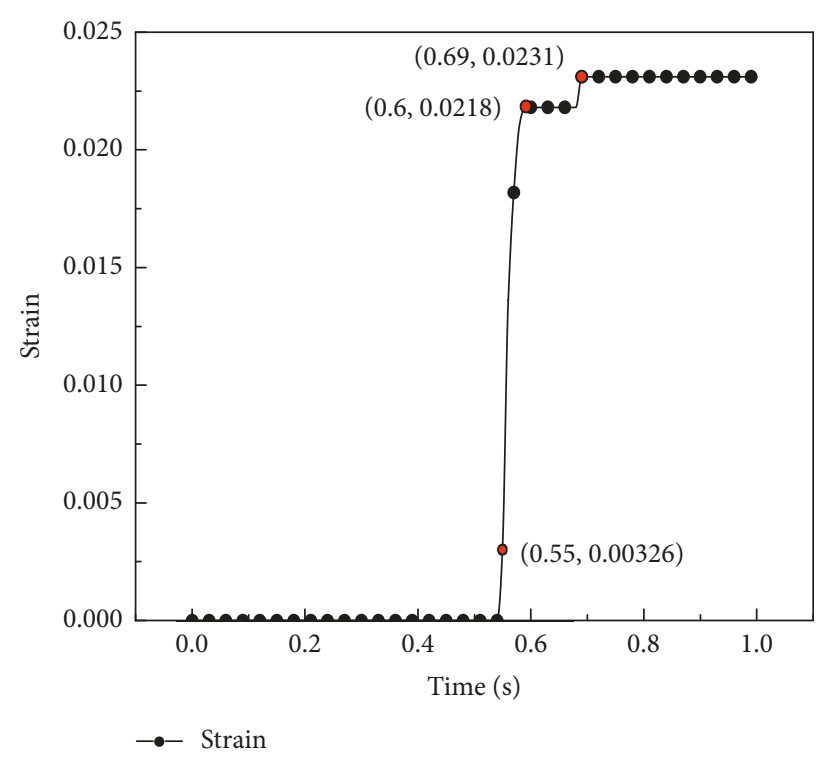

FIgURE 21: Time-history curve of the strain at impact A.

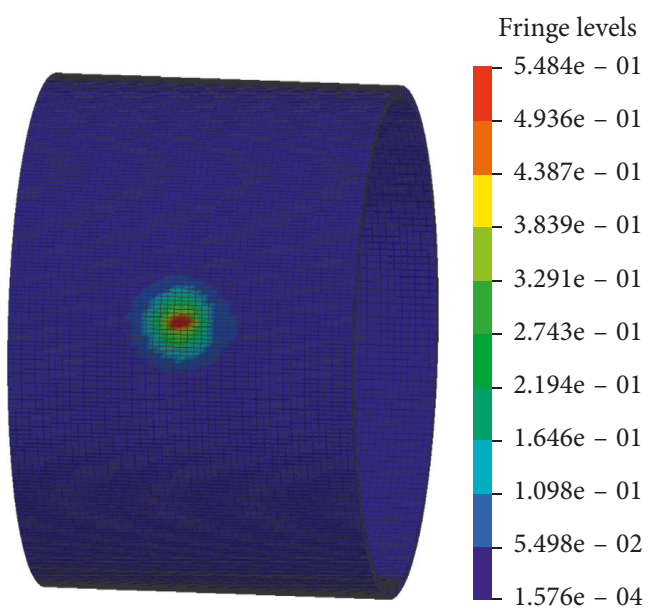

(a)

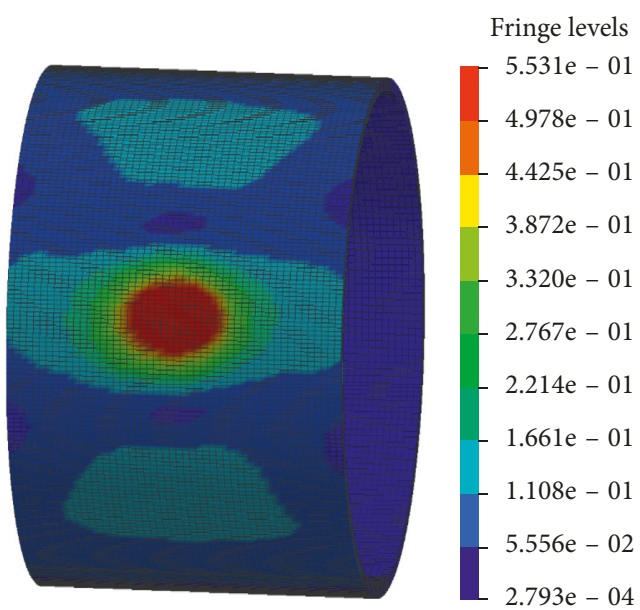

(b)

FIgURE 22: Stress nephograms of impact A within $10 \mathrm{~m}$. (a) $0.55 \mathrm{~s}$ nephogram. (b) $0.58 \mathrm{~s}$ nephogram.

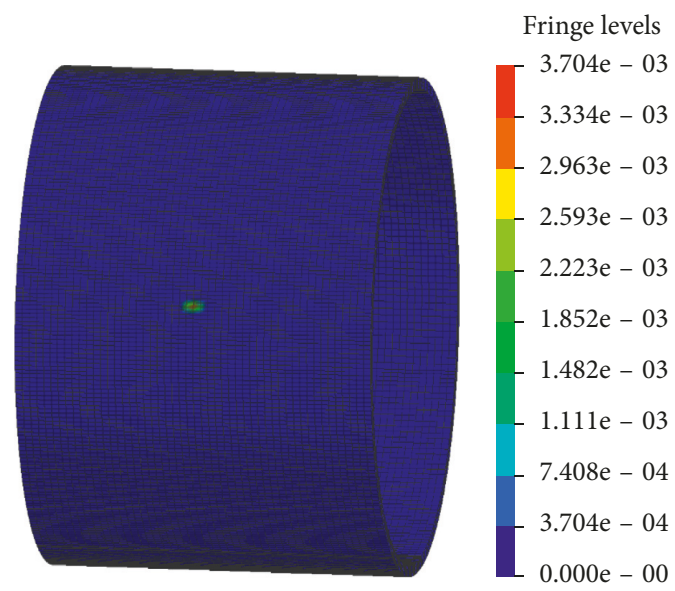

(a)

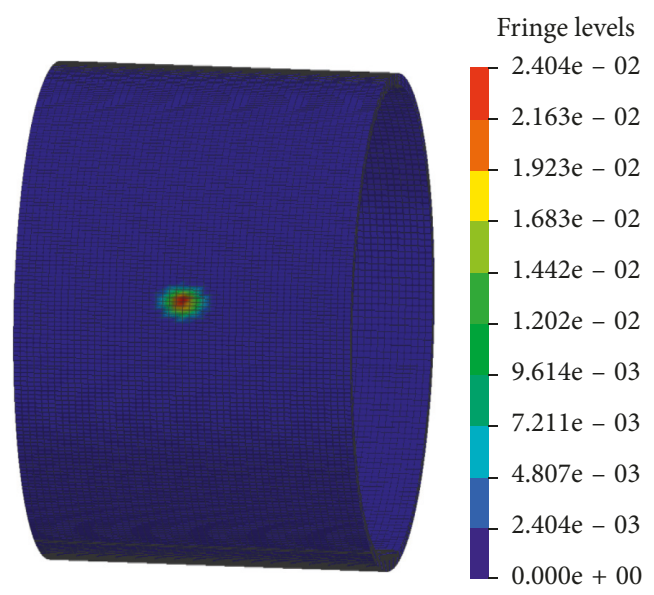

(b)

Figure 23: Strain nephograms of impact A within $10 \mathrm{~m}$. (a) $0.55 \mathrm{~s}$ nephogram. (b) $0.66 \mathrm{~s}$ nephogram. 
According to the passengers' safety evaluation indicators, the damage area can be divided into a moderate injury area, light injury area, and safety area under the extreme conditions, which are $2.2,12.2$, and $85.6 \mathrm{~m}$, respectively.

The stress and strain are the largest near the impact point, at $0.541 \mathrm{GPa}$ and 0.0231 , respectively. Other than the impact point, the stress of the key parts (such as the joints between anchor cables and tunnels, the connections between two tunnel pipe sections and the connection between tunnel and coastal) is complicated. Considerable attention should be paid to the actual build process. The seawater still had a certain effect on the tunnel after the collision, and preventive measures should be taken.

\section{Data Availability}

The data used to support the findings of this study are available from the corresponding author upon request.

\section{Conflicts of Interest}

The authors declare no potential conflicts of interest with respect to the research, authorship, and/or publication of this article.

\section{Acknowledgments}

This work was supported by the National Natural Science Foundation of China (Grant no. 51708042) and National Natural Science Foundation of Shaanxi Province (Grant no. 2019JQ-008).

\section{References}

[1] S. P. Jiang and Q. X. Li, "Development of conceptual design, dynamic analysis theory and model experiment of submerged floating tunnels," Tunnel Construction, vol. 38, no. 7, pp. 352-359, 2018.

[2] Y. Q. Xiang and Y. Yang, "Challenges and technical ideas for the construction of Chinese coastal cross-strait channels," China Municipal Engineering, vol. 5, pp. 1-5, 2016.

[3] J. T. Mai and B. S. Guan, "Submerged floating tunnel," Tunnel Construction, vol. 27, no. 5, pp. 20-23, 2007.

[4] S. Morita, T. Yamashita, and Y. Mizuno, Earthquake Response Analysis of Submerged Floating Tunnels Considering Water Compressibility, International Society of Offshore and Polar Engineers, Osaka, Japan, 1994.

[5] R. Carpaneto, "The dynamic seismic analysis of SFT," in Proceedings of the International Conference on Submerged Floating Tunnels, Sandnes Norway, May 1996.

[6] P. Fogazzi and F. Perotti, "The dynamic response of seabed anchored floating tunnels under seismic excitation," Earthquake Engineering \& Structural Dynamics, vol. 29, no. 3, pp. 273-295, 2000.

[7] W. Chen and G. Huang, "Seismic wave passage effect on dynamic response of submerged floating tunnels," Procedia Engineering, vol. 4, pp. 217-224, 2010.

[8] L. Martinelli, G. Barbella, and A. Feriani, "A numerical procedure for simulating the multi-support seismic response of submerged floating tunnels anchored by cables," Engineering Structures, vol. 33, no. 10, pp. 2850-2860, 2011.
[9] M. S. Dong, M. Li, Z. Lin, F. Tang, and S. P. Jiang, "Dynamic response of the submerged floating tunnel under random seismic excitation," Applied Mathematics and Mechanics, vol. 35, no. 12, pp. 1320-1329, 2014.

[10] J. H. Lee, S. I. Seo, and H. S. Mun, "Seismic behaviors of a floating submerged tunnel with a rectangular cross-section," Ocean Engineering, vol. 127, pp. 32-47, 2016.

[11] S.-I. Seo, M. Sagong, and S.-W. Son, "Global response of submerged floating tunnel against underwater explosion," KSCE Journal of Civil Engineering, vol. 19, no. 7, pp. 2029-2034, 2015.

[12] S.-I. Seo, H.-S. Mun, J.-H. Lee, and J.-H. Kim, "Simplified analysis for estimation of the behavior of a submerged floating tunnel in waves and experimental verification," Marine Structures, vol. 44, pp. 142-158, 2015.

[13] G. Luo, S. K. Pan, X. J. Zhou, J. X. Chen, and B. Q. Dai, "Dynamic response of a submerged floating tunnel during noncontact underwater explosions," China Journal of Highway and Transport, vol. 31, no. 6, pp. 244-253, 2018.

[14] K.-Y. Hong and G.-H. Lee, "Collision analysis of submerged floating tunnel by underwater navigating vessel," Journal of Computational Structural Engineering Institute of Korea, vol. 27, no. 5, pp. 369-377, 2014.

[15] Y. Zhang, M. S. Dong, and F. Tang, "Displacement responses of submerged floating tunnels under impact loads," Applied Mathematics and Mechanics, vol. 37, no. 5, pp. 483-491, 2016.

[16] Y. Xiang and Y. Yang, "Spatial dynamic response of submerged floating tunnel under impact load," Marine Structures, vol. 53, pp. 20-31, 2017.

[17] Y. Q. Xiang, Z. Y. Chen, and Y. Yang, "Research development of method and simulation for analyzing dynamic response of submerged floating tunnel," China Journal of Highway and Transport, vol. 30, no. 1, pp. 69-76, 2017.

[18] Z. Wu and G. Mei, "Dynamic response analysis of cable of submerged floating tunnel under hydrodynamic force and earthquake," Shock and Vibration, vol. 2017, Article ID 3670769, 14 pages, 2017.

[19] Y. M. Mao, W. Y. Wu, G. L. Chen, and Y. C. Gong, "Numerical simulation of high velocity impact problems with $\mathrm{SPH}$ method," Journal of PLA University of Science and Technology (Natural Science), vol. 4, no. 5, pp. 84-87, 2003.

[20] Z. X. Xu, W. H. Tang, and Y. Luo, "Applications of the smoothed particle hydrodynamics method to hypervelocity impact simulations," Explosion and Shock Waves, vol. 26, no. 5, pp. 53-58, 2006.

[21] G. Yang, X. Han, and S. Y. Long, "Simulation of underwater explosion near air-water surface by SPH method," Engineering Mechanics, vol. 25, no. 4, pp. 204-208, 2008.

[22] L. B. Lucy, "A numerical approach to the testing of the fission hypothesis," The Astronomical Journal, vol. 82, pp. 1013-1024, 1977.

[23] M. B. Liu and G. R. Liu, "Smoothed particle hydrodynamics (SPH): an overview and recent developments," Archives of Computational Methods in Engineering, vol. 17, no. 1, pp. 2576, 2010.

[24] S. Tariverdilo, J. Mirzapour, M. Shahmardani, R. Shabani, and C. Gheyretmand, "Vibration of submerged floating tunnels due to moving loads," Applied Mathematical Modelling, vol. 35, no. 11, pp. 5413-5425, 2011.

[25] Y. Q. Zhang, W. J. Cai, J. C. Li, and Z. J. Wang, "Application of a FEM/SPH coupling method to Torpedo water entry," Torpedo Technology, vol. 25, no. 1, pp. 1-6, 2017.

[26] L. Tian and F. Huang, "Numerical simulation method for ship-bridge collision considering fluid effect," Engineering Mechanics, vol. 32, no. 8, pp. 120-128, 2015. 
[27] Y. Cao, P. Wang, X. Jin, J. Wang, and Y. Yang, "Tunnel structure analysis using the multi-scale modeling method," Tunnelling and Underground Space Technology, vol. 28, pp. 124-134, 2012.

[28] LSTC, LS-DYNA_Manual_Volume_I_R9.0, Livermore Software Technology Corporation, Troy, MI, USA, 2016.

[29] X. H. LE and W. Q. KE, Safety Limits for the Effects of Surface Ship Shock on Man, GJB 2689-96, Military Standard Publishing Department of Commission of Science Technology and Industry for National Defense, Beijing, China, 1996. 


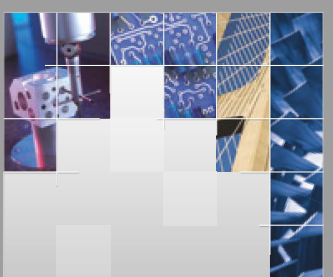

\section{Enfincering}
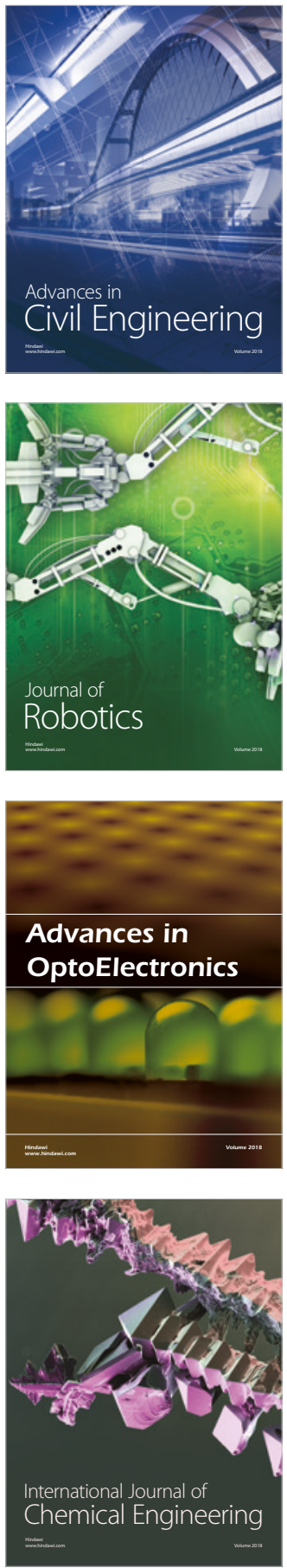

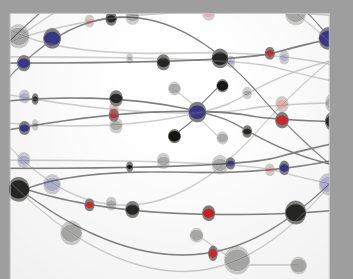

\section{Rotating \\ Machinery}

The Scientific World Journal

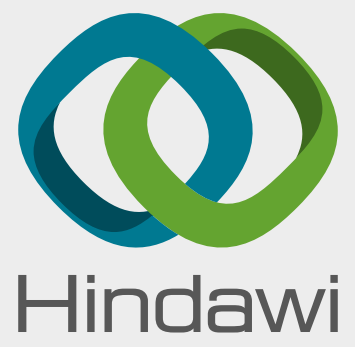

Submit your manuscripts at

www.hindawi.com
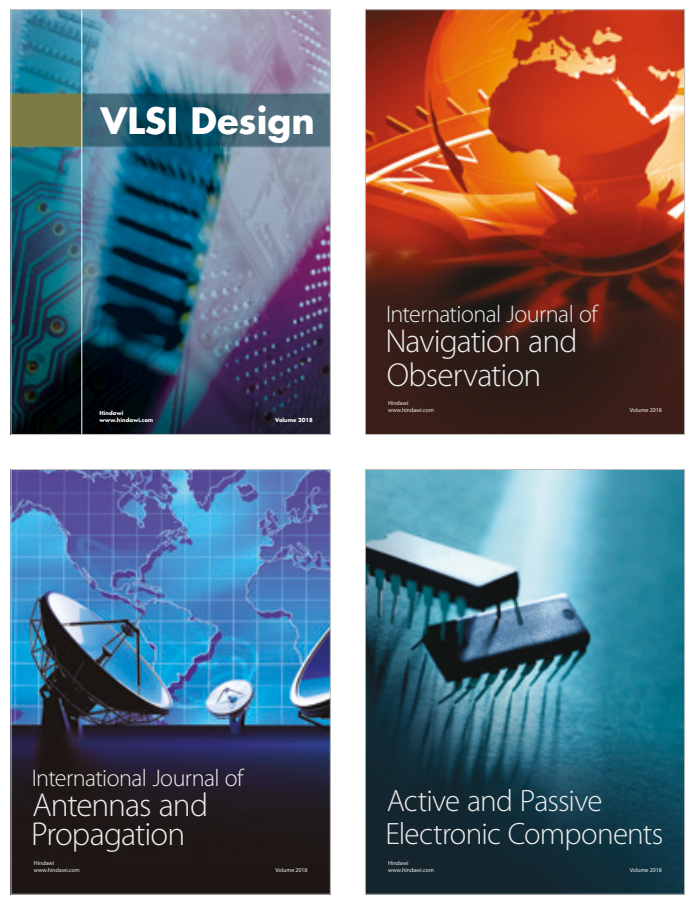
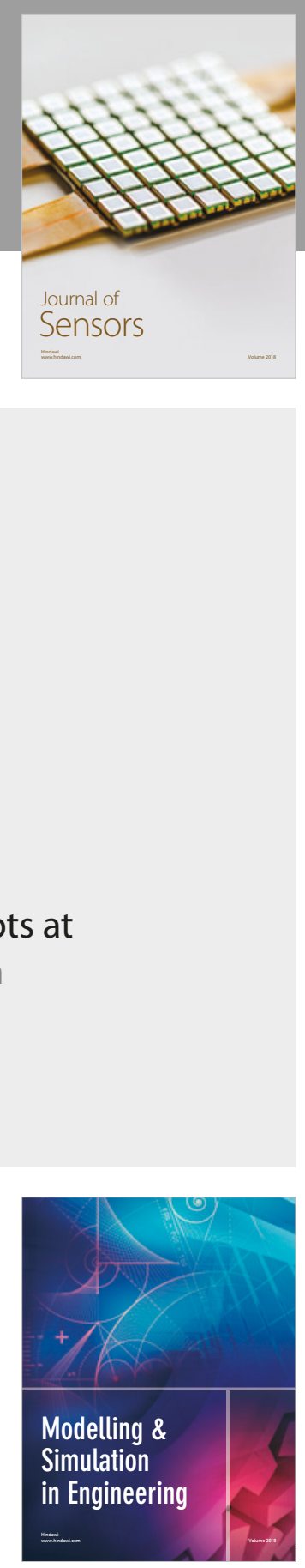

\section{Advances \\ Multimedia}
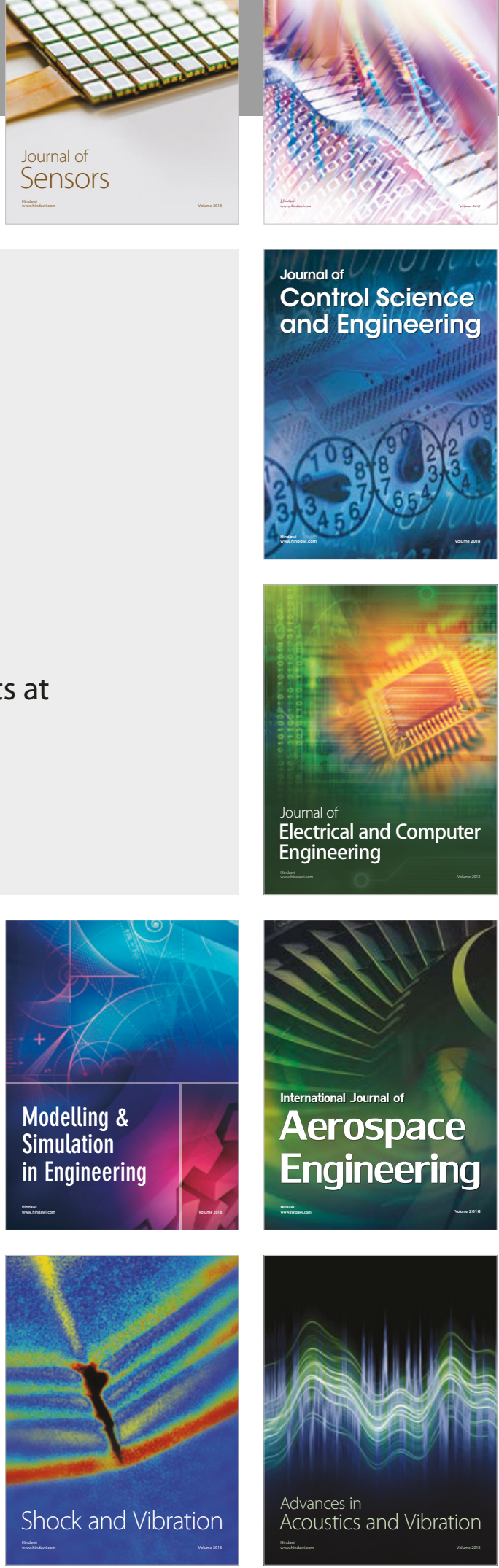